\title{
Annual and Semi-annual Variations of the Observed foF2 in a High Solar Activity Year
}

\author{
Xiao-yin $\mathrm{Li}^{1,2}$ and $\mathrm{Tao} \mathrm{Yu}^{3, *}$ \\ (Manuscript received 8 April 2002, in final form 11 December 2002)
}

\begin{abstract}
By the Fourier series expanding method, the observed F2 layer critical frequencies ( $\mathrm{foF} 2$ ) globally over 70 stations in a high solar activity year of 1958, are used to analyze the annual and semi-annual variations of foF2, and the world wide distribution features of their amplitude and phase in daytime and nighttime are studied in detail. The results for foF 2 annual and semi-annual variation are summarized as follows. The midnight $(2: 00$ LT) foF2 annual variations are noticeable in both hemispheres at mid-high latitudes, and their amplitudes are slightly larger in far pole regions than in near pole regions. Generally, at most stations, the midnight foF2 reach the maximum in summer, and no winter anomaly can be discerned. While in daytime (14:00 LT), there are pronounced annual variations with large amplitude in both hemispheres at mid-high latitudes. After carefully studying their phases, we find that these annual variations usually peak in winter, which indicate all the variations are classic winter anomaly. However, the winter anomaly is very weak in the equatorial zone and not even perceivable in South America. Moreover, the amplitude of daytime foF2 semi-annual variation is generally small in near pole regions and large in far poles region of both hemispheres. Compared with their annual component, the semi-annual variations in the tropical region are significant. Their phase distributions reveal that the semi-annual variation usually peaks in March and April.

In order to explain the results mentioned above, we studied the atomic/ molecular ratio $\left[\mathrm{O} / \mathrm{N}_{2}\right]$ and confirmed that the noon foF2 annual variations prevailing in mid-high latitudes are caused largely by the annual variation of $\left[\mathrm{O} / \mathrm{N}_{2}\right]$. As the noon foF 2 semi-annual variations pronounced in far pole
\end{abstract}

${ }^{1}$ Department of Physics, East China Normal University, Shanghai, P. R. China

${ }^{2}$ Department of Physics and Technology, Wuhan University of Technology, Wuhan, P. R. China

${ }^{3}$ Wuhan lonospheric Observatory, Wuhan Institute of Physics and Mathematics, The Chinese Academy of Sciences, Wuhan, P. R. China

${ }^{*}$ Corresponding author address. Dr. Tao Yu, Wuhan Ionospheric Observatory, Wuhan Institute of Physics and Mathematics, The Chinese Academy of Sciences, Wuhan, 430071, P. R. China;

E-mail: yut1975@hotmail.com 
regions, we should consider the contribution of $\left[\mathrm{O} / \mathrm{N}_{2}\right]$, the solar zenith angle, the solar-driven low/mid-latitude thermospheric circulation and the magnetospherically driven high-latitude circulation. Moreover, we suggest that foF 2 semi-annual variations appearing in the equatorial zone are closely related to other semi-annual variations in the upper atmosphere, such as the semi-annual variation of $\left[\mathrm{O} / \mathrm{N}_{2}\right]$, the thermospheric circulation, the geomagnetic activities and even the ionospheric electrical field.

\section{(Key words: foF2 annual variation, foF2 semi-annual variation, Winter anomaly)}

\section{INTRODUCTION}

Early in 1930's, Chapman had predicted that the electron concentrations in the ionosphere vary regularly with the solar zenith angle as the well-known Chapman layer, so any departure from 'solar-controlled' behavior in the ionosphere is originally taken as 'anomaly' (Rishbeth 1998). In the real ionosphere, the F2 layer is rather an 'anomaly' than controlled by the solar zenith angle as the Chapman theory predicted. There are many 'anomalies' that are wellknown in the F2 layer (Rishbeth 1998, 2000b; Wills et al. 1994), such as the 'equatorial F2layer anomaly' of electron concentration, the 'winter anomaly', the 'seasonal anomaly' and the 'semi-annual anomaly' of foF 2 . As earlier as 1936, Berkner et al. mentioned the annual variation in the ionosphere concerning the upper atmosphere. After the first IGY of 1958, Yonezawa and Arima (1959) discussed the winter anomaly, the annual anomaly, and the semiannual anomaly in mid-low latitudes in detail. With the global observed data, Torr and Torr (1973) for the first time constructed global maps to show regions where noon foF2 is greatest in summer, in winter, or at equinox. Also with global data, Yu et al. (2002) studied the regional characteristics of global NmF2 in six years of high solar activity, but restrict in the daytime $\mathrm{NmF}$ 2. It should be mentioned that Balan et al. (1998) reported the annual variations of ionosphere and thermosphere during the solar maximum period in the East Asia. Later, Ma et al. (2002) and Liao et al. (2000) analyzed the semi-annual variations of foF2 and Equatorial Electrical Jet by observed data, and discussed their possible physical cause. Lal (1998) reported semi-annual variation of the solar wind and the other geophysical phenomena. All of these observing and experimental results developed a better way for us to reveal and understand the phenomena of annual and semi-annual variations in the ionosphere, and give birth to the following extensive assumptions for those phenomena.

There are many hypotheses to explain those anomalies been proposed, which can be concluded in the following three kinds: (1) Yonezawa and Arima (1959) considered that, from summer to winter, the flux of ionizing radiation received on the earth's upper atmosphere is increasing as decreasing of the distance between the sun and the earth, and the electron concentration increase as its photo ionizing production increasing too. The variation from summer to winter is correct in its phase, but the $6 \%$ difference of the ionizing radiation flux caused by the $3 \%$ change of solar-earth distance, which cannot successfully produce more than $20 \%$ 
variation of the electron concentration in the ionosphere. (2) Thermal explanations, Appleton and Ingram (1935) first suggest that the upper atmosphere would be hotter and more expanded in the summer than in the winter, so the neutral concentration become lower in summer, and the NmF2 which approximately proportional to the neutral concentration, tend to become smaller in the summer too. From winter to summer, the NmF2 would increase as decreasing of the solar zenith angle, when the Nmf2 increment caused by the solar zenith angle is inadequate to compensate the $\mathrm{NmF} 2$ decrement caused by the thermal expansion of the upper atmosphere, so $\mathrm{Nmf2}$ will decrease as a whole. But thermal expansion just able to affect the distributions of the ionization, it cannot account for the observed fact of increasing of the total electron concentration (TEC) from summer to winter. (3) Chemical explanation, Rishbeth and Setty (1961), Wright (1963) both recognize the change of chemical composition in the upper atmosphere, such as the atomic-molecular ratio [O/ $\left.\mathrm{N}_{2}\right]$, could account for the variation of $\mathrm{NmF} 2$ in the daytime. Subsequently, Johnson (1964) and King (1964) suggested that the thermospheric circulation from the summer hemisphere to the winter one could change the $\left[\mathrm{O} / \mathrm{N}_{2}\right]$ ratio, and could change the $\mathrm{NmF} 2$ in the end. Extending this ideal to the magnetic storms, Duncan (1969) interpreted physical mechanism of the magnetic storms. Up to now, the thermospheric circulation combining with the change of chemical composition remains the principal theory to explain the anomalies in the ionosphere.

With the numerical method, there are many progresses in the research of understanding and explanation of ionospheric anomalies. Millward et al. (1996) tried to explain the regional difference of seasonal and semi-annual characteristics at mid-latitudes by using of the CTIP model, and found that the large offset of the geographic pole and the geomagnetic pole in different sector is a contributor. Later, a mechanism named 'thermospheric spoon' was proposed by Fuller-Rowell (1998) to explain the cause of the global semi-annual thermospheric density variation, as well as in the Ionosphere. Recently, Zou et al. (2000) reproduced annual and semi-annual variation of $\mathrm{NmF} 2$ only including the global thermospheric circulation without invoking other causes. A companion paper was presented by Rishbeth (2000a), in which the physical details were discussed.

In this paper, we used the record data in a high solar activity year of 1958 to analyze the annual and semi-annual variations of foF2. Firstly, we decompose the original data into terms of average value, annual component, and semi-annual component. Secondly, global distribution maps for the annual and semi-annual components are presented and their important characteristic are summarized in the daytime and nighttime. Finally, with more emphasis we placed on to discuss how far the phenomena we study could be explained by the theories in current.

Focusing on mid-latitudes and equatorial zone, we excluded the polar station. Moreover we left out stations whose observed data are fragmentary. In the end, we have the data from 70 stations all over the world.

\section{METHODOLOGY AND EXAMPLE}

\subsection{Analysis Method}

Our data are from the CD-ROM available from NOAA. The disk gives data covering 
more than 100 global stations, spanning from 1958 to 1989, including the critical frequencies of F2 layer ( $\mathrm{foF} 2$ ). In order to study foF2 annual and semi-annual variations in high solar activity year, we select the data in 1958, the highest solar activity year in current. Since we are interested in foF 2 semi-annual and annual variations, we express foF 2 at given local time as three terms, similar with Rishbeth et al. (2000c) and Yu et al. (2002), which represent average value, annual component and semi-annual component respectively.

$$
f o F 2(d, L T)=A_{0}(L T)+A_{i}(L T) \cos \frac{2 \pi}{365}\left(d-D_{1}(L T)\right)+A_{2}(L T) \cos \frac{4 \pi}{365}\left(d-D_{2}(L T)\right),
$$

where $\mathrm{LT}$ is local time, $\mathrm{d}=1,2, \ldots, 365 . A_{1}, A_{2}$ are the amplitudes of foF2 annual and semiannual components in a certain local time and in units of $\mathrm{MHz}$, and $D_{1}, D_{2}$ are the phases corresponding to those components and in units of days, zero phase meaning the maximum is on 1 January. After studying the coefficients carefully, we may distinguish whether foF 2 variation is an annual pattern or a semi-annual one and when those variations reach their peaks. In the end, we show the coefficients of annual and semi-annual variations on a world map to investigate their regional feature and compare these variations with other anomalies in the ionosphere.

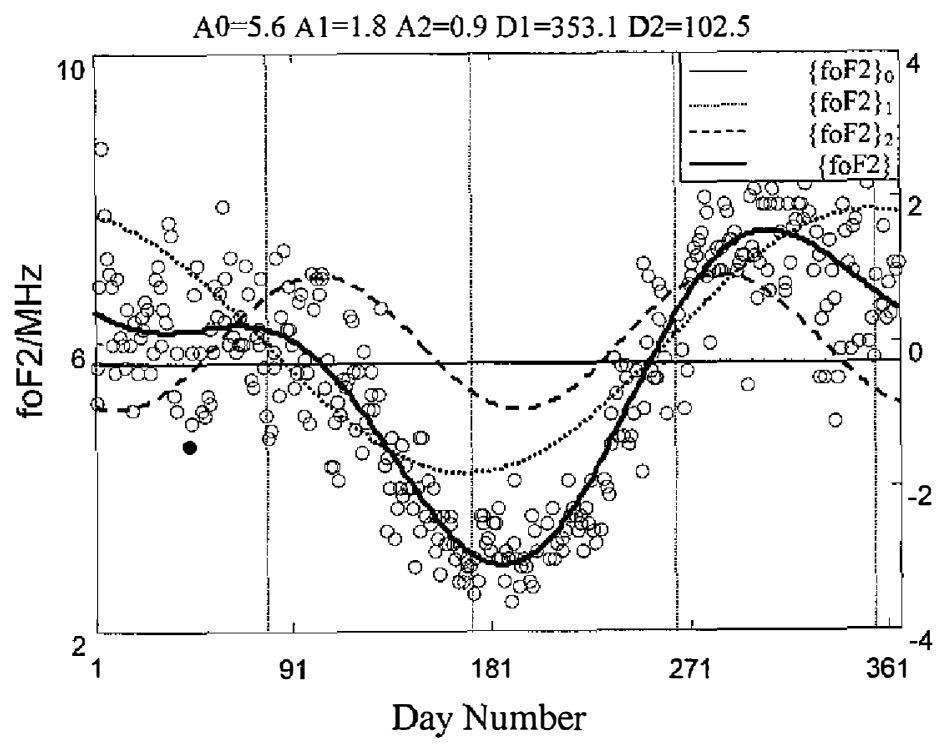

Fig. 1. The midnight (2:00 LT) observed foF2 (circles) and regression results (bold solid line) at Johannesburg Station in 1958. The coefficients in Equation (1) are shown on top of the figure. 


\subsection{An Example}

The nighttime foF2 at Johannesburg Station $\left(28.1^{\circ},-26.1^{\circ}\right)$ and its results regressed by Equation (1) are shown in Fig. 1. Since foF2 itself exhibits a strong day-to-day variation (Forbes et al. 2000; Rishbeth and Mendillo 2001), the observed data (circles) scatter away from the regression result (bold solid line), as illustrated in Fig. 1. In fact, we adopt this regression method to smooth out short period oscillation in observed foF2, so that the annual and semiannual variations may be distinguished. In the end, we use the regression results of foF 2 to analyze their annual and semi-annual variations instead of the original observed data.

In Fig. 1, the four vertical dotted lines denote March equinox, June solstice, September equinox and December solstice respectively. The horizontal thin solid line denotes the yearly average of foF $2\left(\{\mathrm{foF} 2\}_{0}\right)$. The dotted line denotes the value of annual component ( $\left.\{\mathrm{foF} 2\}_{1}\right)$. In Fig. 1, the amplitude of foF2 annual component $A_{1}=1.8 \mathrm{MHz}$ and its phase $D_{1}=353.1$ days, and the annual variation reaches its peak close to summer solstice in the southern hemisphere. So there is no winter anomaly for nighttime foF2 at Johannesburg Station. The dashed line denotes the value of semi-annual component ( $\{\mathrm{foF} 2\}_{2}$, ). The semi-annual amplitude $A_{2}=0.9$ $\mathrm{MHz}$, which is slightly smaller than that of annual one, and its phase $D_{2}=102.5$ days, so the foF2 semi-annual variation reaches its peak close to the March equinox. Therefore, the nighttime foF 2 over Johannesburg has a dominant annual variation and a weak semi-annual one. In the following, we discuss the foF 2 annual and semi-annual variations in nighttime and in daytime. After many tests, we find that there is no obvious influence on the results whether we use the data in a single local time or the average value over several local hours. So, we take foF2 at 2:00 LT as the sample for nighttime and foF2 at 14:00 LT as the sample for daytime respectively.

\section{RESULTS}

\subsection{Annual Variation of foF2}

After comparing of foF2 difference in summer and in winter, Torr and Torr (1973) constructed global maps to show the regional distribution for the foF2 annual or seasonal variation; and it was a good method to distinguish different types of 'anomaly' in different regions. Nevertheless, it provides only a rough indication of seasonal or annual variation, without details of amplitudes and phases. Its reliability is clearly affected by the uneven distribution of stations over the globe (Rishbeth 1998). Moreover, Yu et al. (2002) work only deals with the case of daytime, and lack of the details in physical mechanism discussion. In this paper, we use both the noon and midnight foF 2 over 70 stations in a high solar activity year, and in order to present the amplitudes and phases of the annual and semi-annual variation on a world map , to investigate their global features, and with more effort on their day-night difference. In the following global maps, we mark circles in places where the stations are located. The radius denotes the normalized annual amplitudes $\left(A_{1} / A_{0}\right)$; the plus sign ' + ' and cross ' $x$ ' show the phase information. We class the phases into two groups. One group is ' + ' phase, which implies that the foF2 annual variation reaches its peak in the days closer to the December solstice 
rather than the June solstice. The other group is ' $\mathrm{x}$ ' phase, which implies the foF2 annual variation reaches its peak in the days closer to the June solstice rather than December solstice.

Global distributions for midnight (2:00 LT) foF2 annual variation are shown in Fig. 2a. Its background is a world map. The northem and southem magnetic poles are marked by asterisks. We summarize the nighttime foF 2 annual variation characters as follows. There are annual variations in the mid-high latitudes of both hemispheres. Figure 2a shows that circles in the mid-high latitudes regions are larger than those in other regions. The ' $x$ ' phases are predominant in the northern hemisphere, namely, the foF2 annual variations are prone to reach their peak at the summer solstice in the northern hemisphere, whereas the ' + ' phases are predominant in the southern hemisphere, namely, the foF2 annual variations are prone to reach their peak at the summer solstice in the southern hemisphere. Therefore, there is no anomaly in both hemispheres, and foF2 varies as Chapman expected-it maximizes in summer and minimizes in winter. Another remarkable feature in Fig. 2a is the amplitudes of midnight foF2 annual variation are smaller in near pole regions, such as North America and Australia, than those in far pole regions, such as Far East and South America. Moreover, the annual amplitudes are very small in the equatorial region.

The noon (14:00 LT) foF2 annual variation is shown in Fig. 2b. A prominent feature is that the amplitudes of annual variation are very large in the northern hemisphere at mid-high latitudes; moreover, the ' + ' phases are predominant in the northern hemisphere and South America while the ' $x$ ' phases are predominant in Ausiria. So, it is much different from the case of nighttime that when is a pronounced winter anomaly prevailing in the mid-high latitudes of both hemispheres, except for South America. Moreover, in North America, the amplitudes of noon annual variation are much greater than those at midnight, whereas in South America and South Africa the annual amplitudes of noon foF2 are even smaller than those at midnight. It is very interesting that at Trelew (a South American Station), the noon annual variation is very large while the midnight annual variation is very small. By contrast at Port Stanley, a station nearby, the noon annual variation is very small while the midnight annual variation is very large. Consistent with the case of nighttime (Fig. 2a), the amplitudes of noon foF2 annual variations in the equatorial zone are much weaker than in other regions.

Plots of the annual variation amplitudes against the geophysical latitude are illustrated in Figs. 3a, b. Both the nighttime and daytime results show that the amplitudes of annual variation decrease with decreasing latitude and the amplitudes are greater at mid-high latitudes and less at lower latitudes. Moreover, in the northern hemisphere, the daytime amplitudes are much greater than those of nighttime, whereas in the southern hemisphere, they are even a little less than those of nighttime. This result is very consistent with the previous works (Yu et al. 2002), in spite of they plots verses the magnetic latitude.

In order to determine when the annual variations reach the maximal value, the phases of foF 2 annual variation in nighttime and daytime are statistically analyzed, the results are shown in Figs. $4 a$, b. In the figures, the $x$-axis denotes months from January to November, and the yaxis indicates how many stations reache the foF 2 peak in a respective month. In the case of nighttime, there are two occurrence peaks for annual variation. One strong peak occurs in June extending to May and August, and a relatively weak peak occurs in December. The statistical result for daytime is shown in Fig. 4b. There is only one very strong occurrence peak of annual 
a

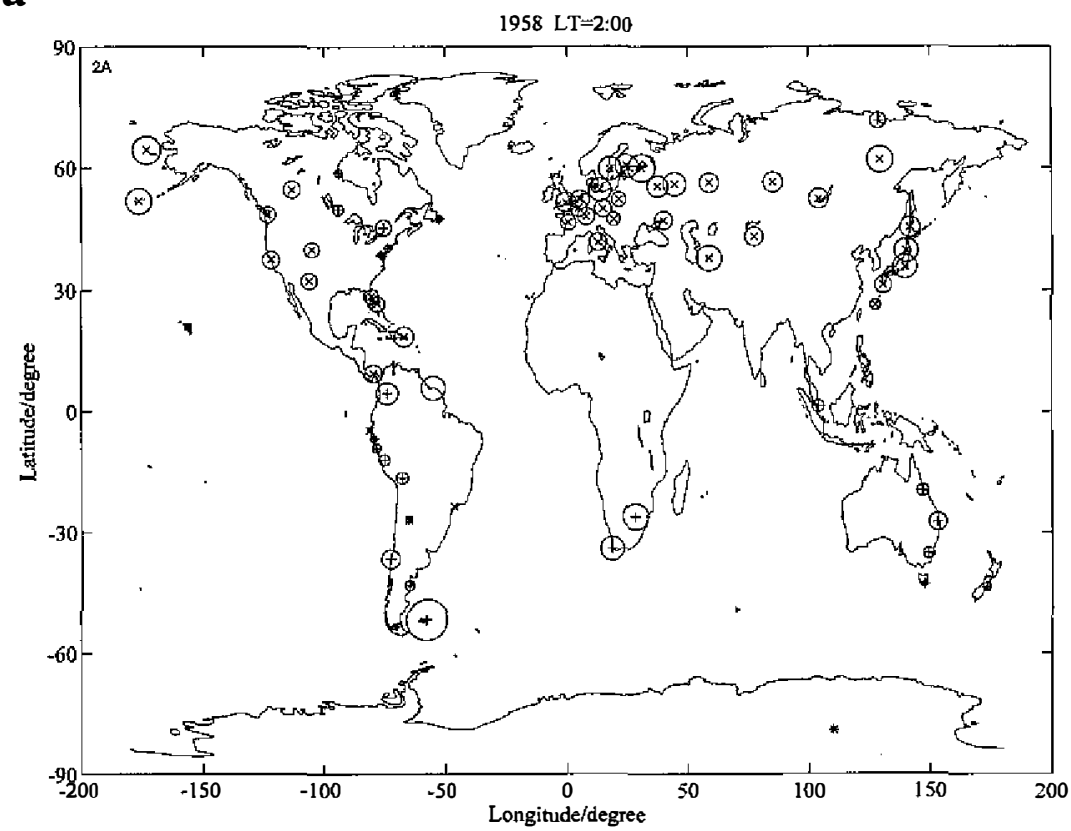

b

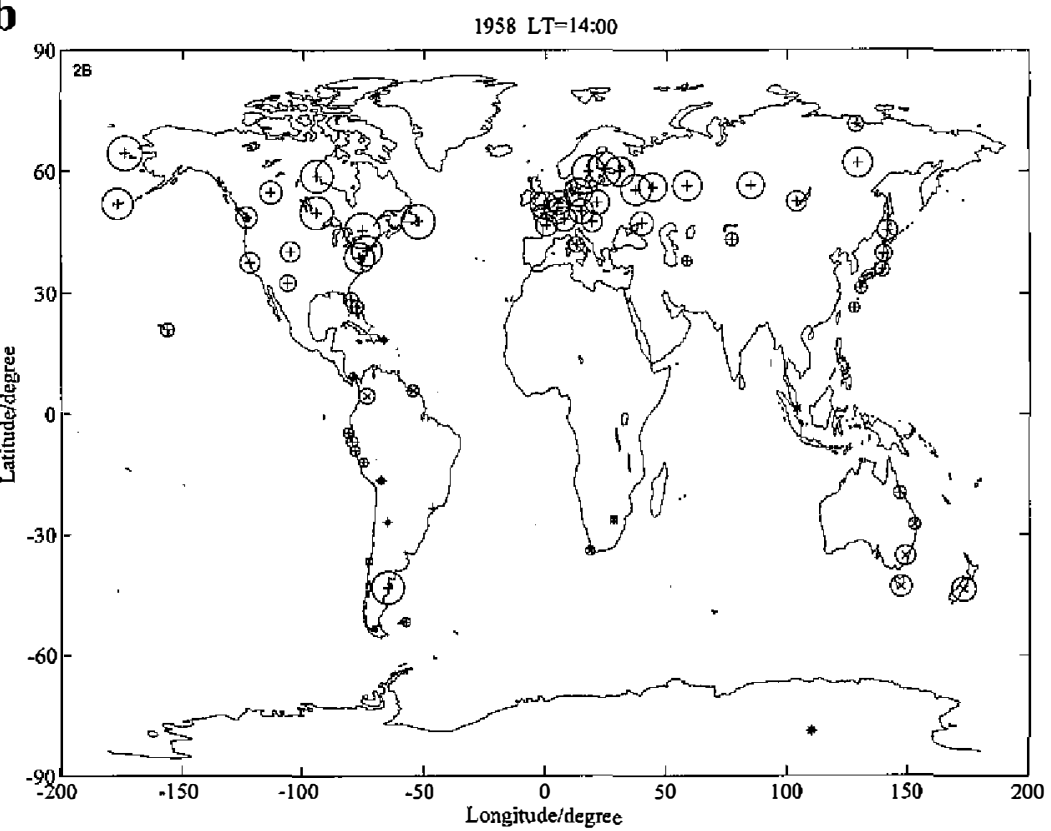

[

Fig. 2. Global distributions maps showing the annual amplitudes at midnight (a) and noon (b) foF2 in 1958. The radius denotes ratio of annual amplitude to meanannual value. The ' + ' phase implies that foF2 annual variation reach its peak in the days closer to December solstice. The cross ' $x$ ' denotes is the opposite to what the plus sign ' + ' does. 
TAO, Vol. 14, No. 1, March 2003

variation in January and December, and this result is because many winter anomaly stations in the northern hemisphere are included in our work. The other weak peak occurring in May is because fewer winter anomaly stations in the southern hemisphere are included. However, very few stations reach the peak in other months.

\subsection{Semi-annual Variation of foF2}

Global distribution maps for midnight (2:00 LT) and noon (14:00 LT) foF2 semi-annual variation in high solar activity years are shown in Figs. 5a, b. In the far pole regions, such as South America, the semi-annual variations of nighttime foF 2 are slightly greater than in the other regions. In North America and Europe, close to the northern magnetic pole, the semiannual variations are very weak. However, in Australia, close to the southern magnetic pole, the semi-annual variations are of some magnitude.

The case of daytime is shown in Fig. 5b. As a global average, the daytime foF 2 semiannual amplitudes are much larger than those of nighttime. In the far pole region, such as South America and the Far East, the semi-annual amplitudes are slightly larger than those in other regions. In North America and Europe, the semi-annual amplitudes are slightly small. Also, the semi-annual variations are of considerable magnitude in Australia. Compared with the annual component, the semi-annual variations in the equatorial region are significant.

The latitude features of foF2 semi-annual variation in nighttime and daytime are shown in Fig. 6. This is different from Fig. 3 where the amplitudes of semi-annual component do not decrease with decreasing latitude. Usually, the amplitudes are distributed as a double hump, which is large at mid-latitudes and a little smaller at equator and very small at high latitudes. In addition, those amplitudes are of nearly comparable magnitudes in both hemispheres. As a global average, the daytime semi-annual amplitudes are much larger than those in nighttime. Moreover, we should noticed that the daytime semi-annual amplitudes are very large at two equatorial stations.

The phases statistical results of foF2 semi-annual variation during nighttime (2:00 LT) and daytime (14:00 LT) are shown in Fig. 7. The $x$-axis denotes the month, the y-axis is station number, and the bin size is one month. Since the period of semi-annual variation is six months, its phase range is from January to June. It may be seen from Figs. 7a, b that both during nighttime and daytime the occurrence maximization is in March and April, and more than 40 stations reach their semi-annual variation peaks in March and April, which amounts to over $80 \%$ of the total stations. Very few stations reach their peaks in other months.

\section{PHYSICAL DISCUSSIONS}

\subsection{Physical Discussion for the Annual Variation at Mid-high Latitudes}

Many researches reported the foF 2 winter anomaly in daytime predominant in mid-high latitudes. Many hypotheses were proposed to explain this phenomenon, of which the theory proposed by Rishbeth and Setty (1961) and Wright (1963) is the most famous. They suggested that a change of atomic/molecular ratio $\left[\mathrm{O} / \mathrm{N}_{2}\right]$ in the upper atmosphere would account for the 


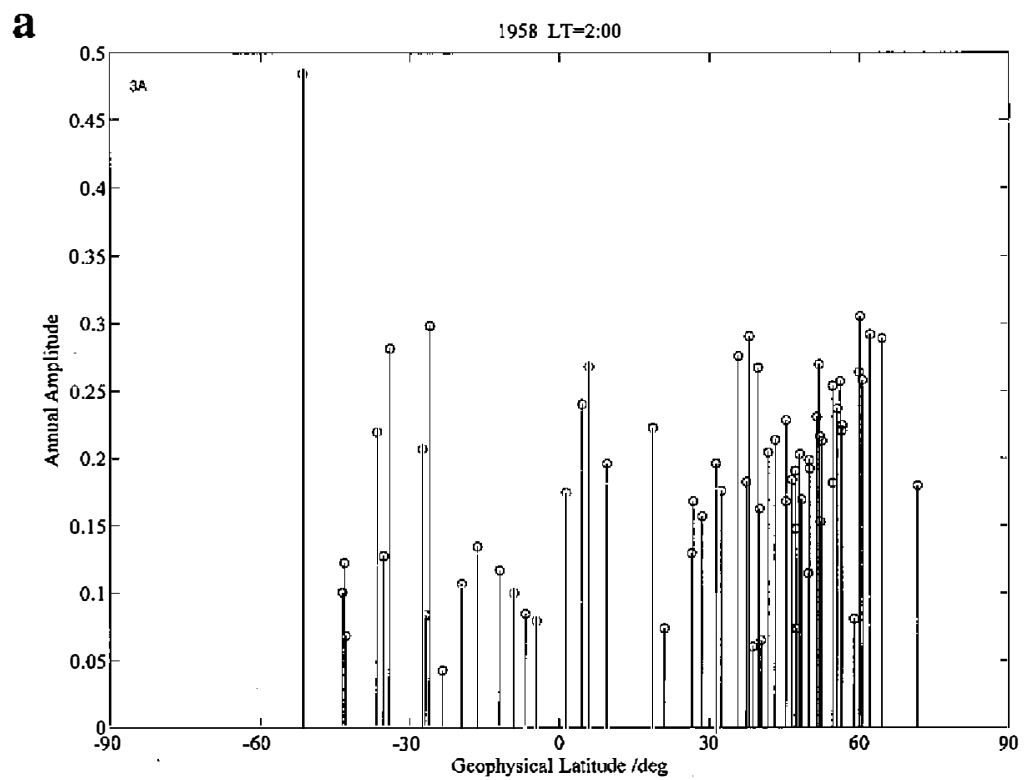

b

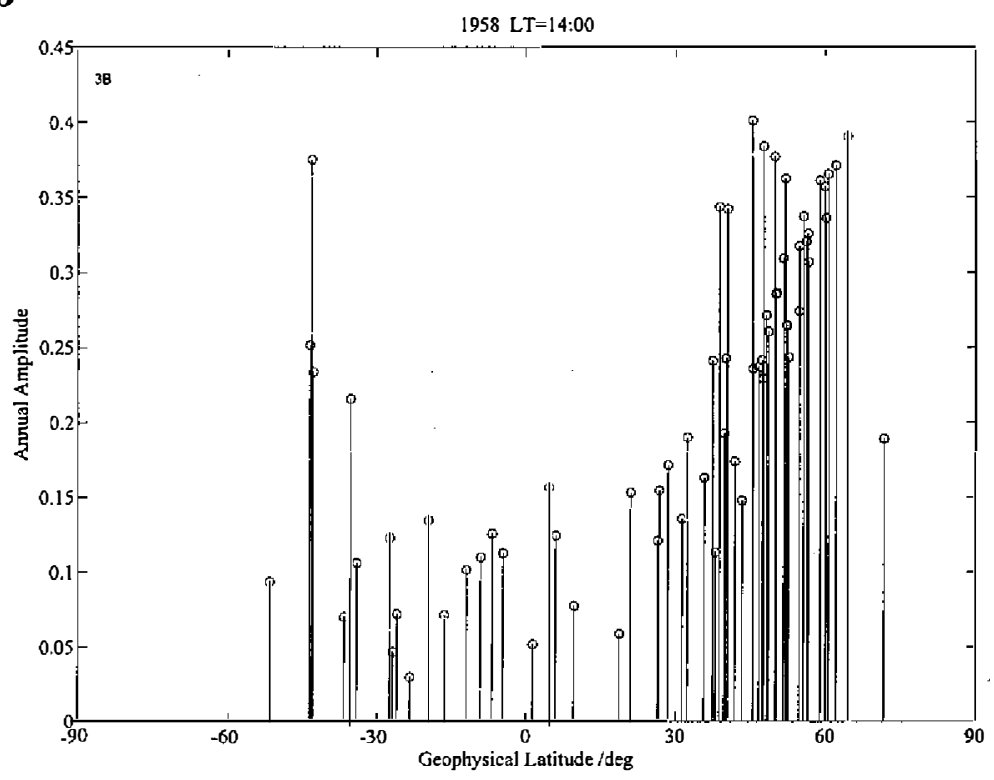

Fig. 3. The amplitude at midnight (a) and noon (b) foF2 in 1958 annual variation plotted versus geophysical latitude, the $y$-axis denotes the normalized amplitude $\left(\mathrm{A}_{1} / \mathrm{A}_{0}\right)$. 
daytime NmF2 variation. Later, Johnson (1964) and King (1964) figured out that the thermospheric circulation from the summer hemisphere to the winter one could change $\left[\mathrm{O} / \mathrm{N}_{2}\right]$ and lead to the variation of $\mathrm{NmF} 2$. Although this theory has been widely discussed in the past decades, we still introduce it briefly, so as to discuss how far our results can be explained by it.

In the daytime, the F2 layer is usually in 'quasi-equilibrium' state, which means that $\partial N / \partial t$ is smaller than other terms in the continuity equation. At the height near the F2 peak, the production and loss terms are roughly in balance, the production term $q$ depends mainly on the atomic oxygen concentration [O], and the loss term $\beta$ depends mainly on the molecular nitrogen concentration $\left[\mathrm{N}_{2}\right]$ with some contribution from molecular oxygen $\left[\mathrm{O}_{2}\right]$. After ignoring the contribution of $\left[\mathrm{O}_{2}\right]$, the electron concentration in the steady-state is given by

$$
N_{e} \sim q / \beta \sim\left[O / N_{2}\right]
$$

Thereafter, the daytime electron concentration near the F2 peak is approxiamately proportional to the atomic/molecular ratio $\left[\mathrm{O} / \mathrm{N}_{2}\right]$. Generally, the neutral wind or the electrical field is prone to shift the $\mathrm{F} 2$ peak to a higher or a lower position; as a consequence, $\mathrm{NmF} 2$ decreases or increases with the increasing or decreasing of the loss term $\beta$, but Equation (2) still is a reasonable approximation of electron density. However, as the production term $q$ vanishes in the nighttime, Equation (2) is not resonable anymore, and dynamic processes such as diffusion, neutral wind and electrical field, come to be significant contributor to the electron concentration.

In the following, we are going to study respectively the noon atomic/molecular ratio [O/ $\mathrm{N}_{2}$ ] annual and semi-annual variation at Rome (8A) and Canberra (8B), and compare them

a

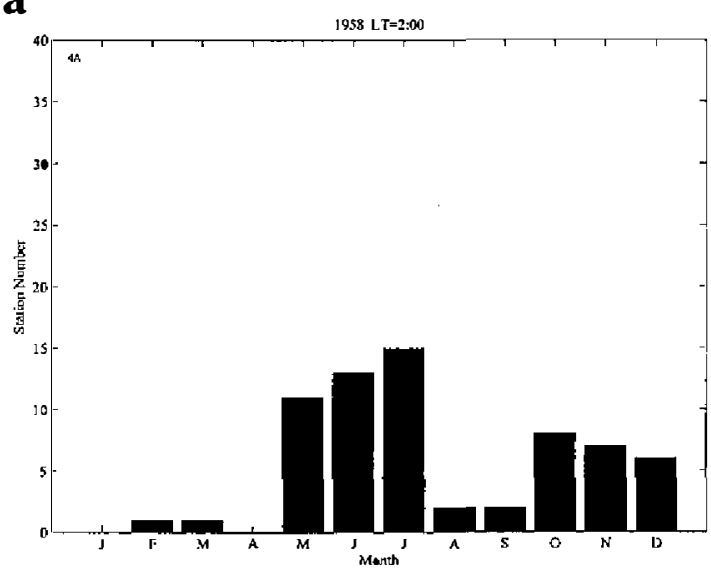

b

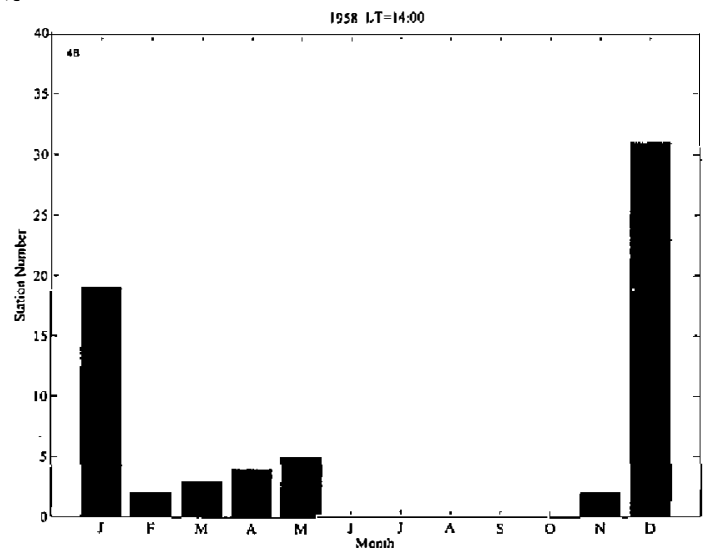

Fig. 4. Phase's statistical results at midnight (a) and noon (b) foF2 annual variation in 1958. The $\mathrm{x}$-axis denotes month from January to November, and the $y$-axis indicates how many stations reached the foF 2 peak in respective month. 
with the variation of observed foF 2 in these stations. $\left[\mathrm{O} / \mathrm{N}_{2}\right]$ is calculated by empirical model MSIS90. In the upper panel of Fig. 8a, the circles and the bold solid lines respectively represent the measured foF2 and the results regressed by Equation (1). In the bottom panel of Fig. $8 \mathrm{a}$, the circles and the bold solid lines respectively represent $\left[\mathrm{O} / \mathrm{N}_{2}\right]$ provided by MSIS 90 and the results regressed by Equation (1). The bottom panel of Fig. 8a shows a pronounced annual variation of $\left[\mathrm{O} / \mathrm{N}_{2}\right]$ over Rome. The normalized annual variation amplitude is 0.27 and the normalized semi-annual variation amplitude is 0.06 , which imply that $\left[\mathrm{O} / \mathrm{N}_{2}\right]$ is rather an annual variation than a semi-annual one. The annual variation phase is 360 days, indicating that $\left[\mathrm{O} / \mathrm{N}_{2}\right]$ reaches its maximum in winter, therefore there is a considerable winter anomaly for $\left[\mathrm{O} / \mathrm{N}_{2}\right]$ at Rome. At the same time, results from the upper panel in Fig. 8a reveal that foF2 in Rome has a dominant annual variation with a normalized amplitude of 0.17 and a phase of 358 days, whereas the normalized semi-annual amplitude is 0.11 , which is nearly of comparable magnitude with the annual amplitude. Seen from the regression results (solid line) in the upper and bottom panel of Fig. 8a, we may conclude that variations of foF 2 and $\left[\mathrm{O} / \mathrm{N}_{2}\right]$ not only have the similar amplitude but also have the similar phase. Figure $8 \mathrm{~b}$ is the case of Canberra. It is clear that the variations of foF 2 and $\left[\mathrm{O} / \mathrm{N}_{2}\right]$ in Canberra fit even better than those of Rome. What's more, both the annual phase and the semi-annual phase of foF 2 and $\left[\mathrm{O} / \mathrm{N}_{2}\right]$ are very much alike. Therefore, we conclude that the change of $\left[\mathrm{O} / \mathrm{N}_{2}\right]$ in the upper atmosphere may contribute to the daytime foF2 annual variation prevailing in mid-high latitudes at least in somewhat (Rishbeth and Setty 1961; Wright 1963).

In order to investigate how far the change of $\left[\mathrm{O} / \mathrm{N}_{2}\right]$ may contribute to foF2 variation in different regions, we calculated the noon atomic/molecular ratio $\left[\mathrm{O} / \mathrm{N}_{2}\right]$ at all the stations mentioned in Fig. 2 with empirical model MSIS90. For a comparable result, we made the global distribution map for $\left[\mathrm{O} / \mathrm{N}_{2}\right]$ annual variation shown in Fig. 9. Figure 9 shows pronounced annual variations of the noon $\left[\mathrm{O} / \mathrm{N}_{2}\right]$ in the mid-high latitudes of both hemispheres, and these annual variations all appear to be winter anomaly. These annual variations seem to be much weaker in the equatorial zone. Comparing Fig. $2 \mathrm{~b}$ with Fig. 9, we see that the global distributions for the noon $\left[\mathrm{O} / \mathrm{N}_{2}\right]$ and the noon foF2 annual variations are similar very much, except in South America, where the noon $\left[\mathrm{O} / \mathrm{N}_{2}\right]$ has obvious winter anomaly but the noon foF2 has not. Further investigating shows that winter anomaly of $\left[\mathrm{O} / \mathrm{N}_{2}\right]$ is noticeable both in the daytime and nighttime, but the winter anomaly of foF2 is just noticeable in the daytime. These phenomena occur because Equation (2) applied just during the daytime. So the winter anomaly of $\left[\mathrm{O} / \mathrm{N}_{2}\right]$ could only lead to the winter anomaly of foF 2 in daytime. In contrast during the nighttime, the dynamic process turns into a significant contributor to foF2, and foF2 is not influenced primarily by $\left[\mathrm{O} / \mathrm{N}_{2}\right]$ any more. So, there is no winter anomaly of foF2 in the nighttime despite of the winter anomaly of $\left[\mathrm{O} / \mathrm{N}_{2}\right]$.

\subsection{Physical Discussion for the Semi-annual Variation at Mid-high Latitudes}

Figures. 5a, b show strong semi-annual variations occurring in the near pole regions and rather weaker semi-annual variations in the far pole, especially in daytime. This phenomenon may be attributed to the change of $\left[\mathrm{O} / \mathrm{N}_{2}\right]$, the solar zenith angle $\chi$, the solar-driven low $/ \mathrm{mid}$ latitude thermospheric circulation and magnetospherically driven high-latitude circulation 
TAO, Vol. 14, No. 1, March 2003

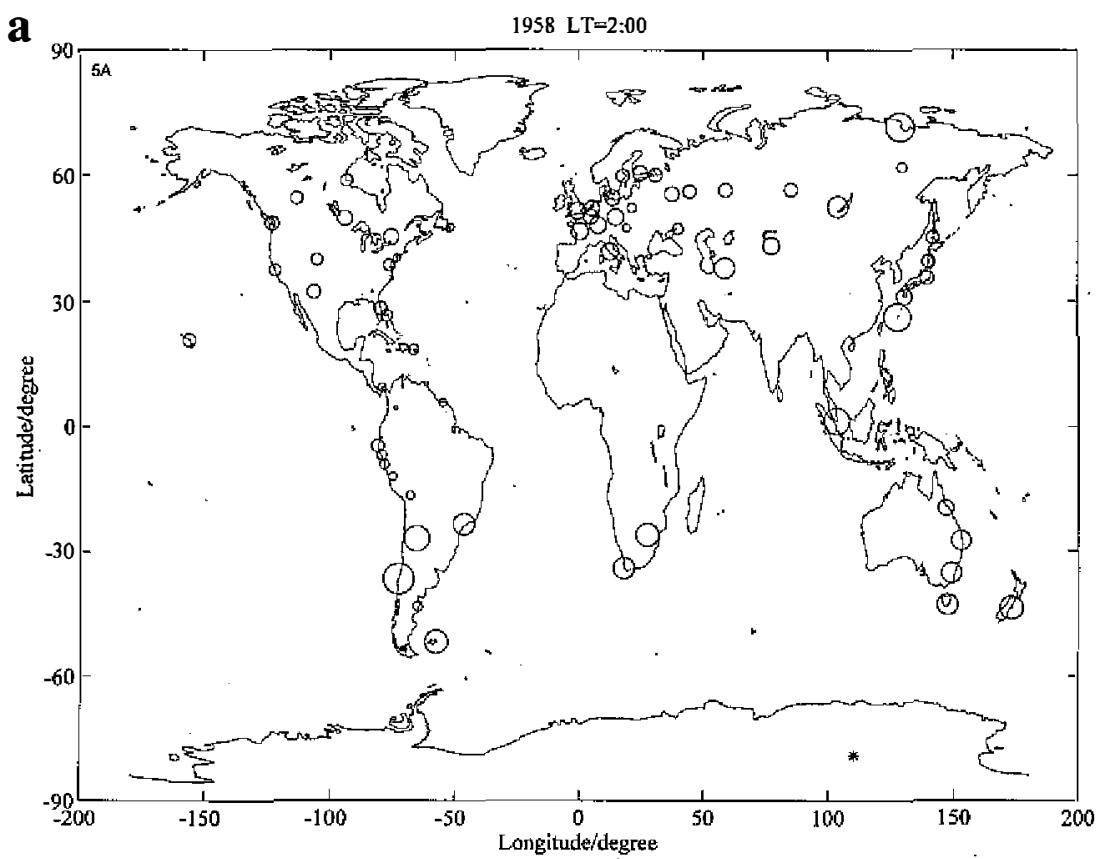

b

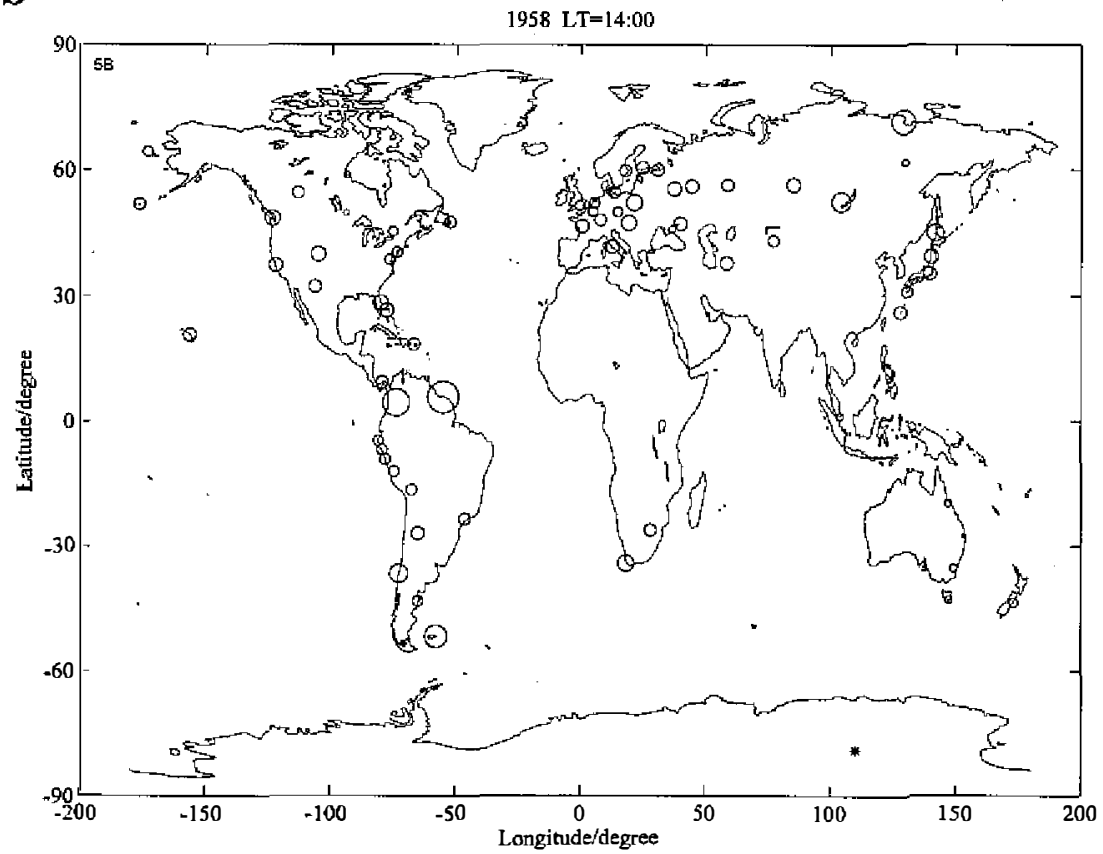

Fig. 5. Global distributions maps at midnight (a) and noon (b) foF2 semi-annual variation amplitudes. The radius denotes the normalized semi-annual amplitudes $\left(\mathrm{A}_{2} / \mathrm{A}_{0}\right)$ 

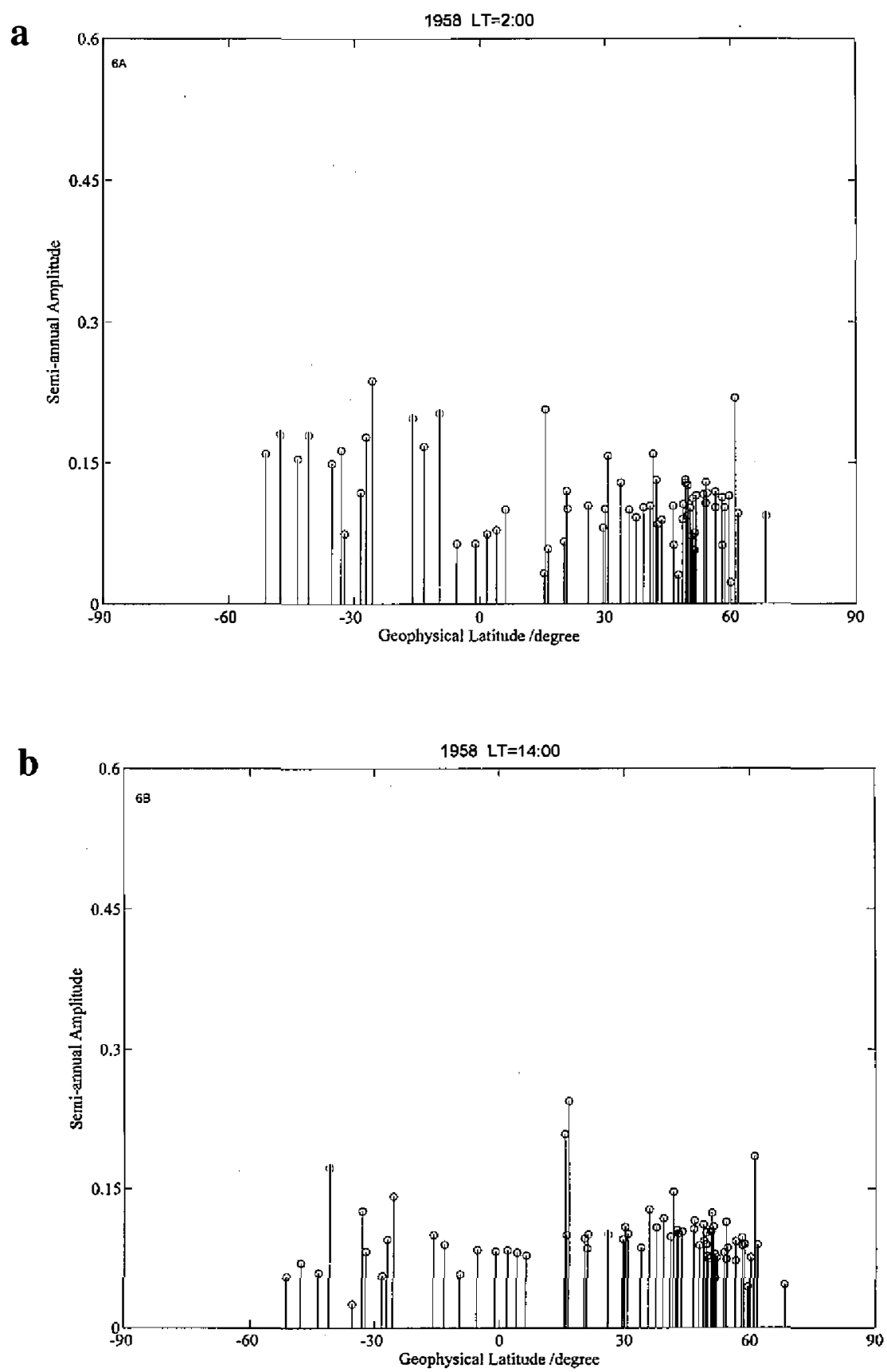

Fig. 6. The amplitude at midnight (a) and noon (b) foF2 semi-annual variation plotted versus geophysical latitude. The y-axis represent the normalized semi-annual amplitude $\left(\mathrm{A}_{2} / \mathrm{A}_{0}\right)$. 
a

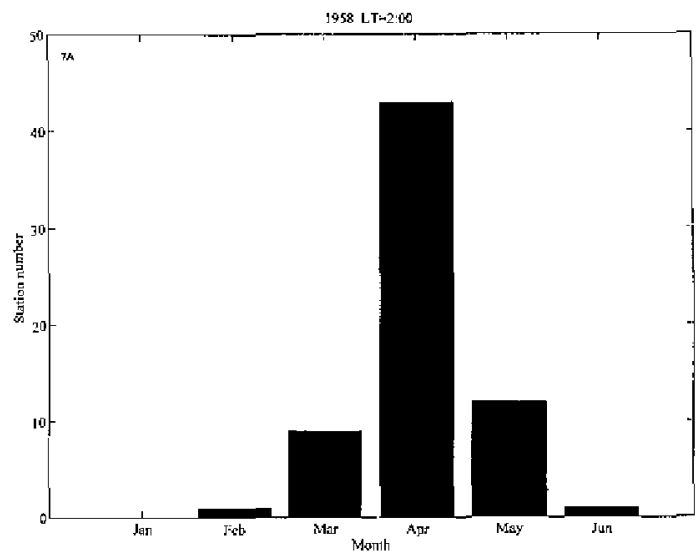

b

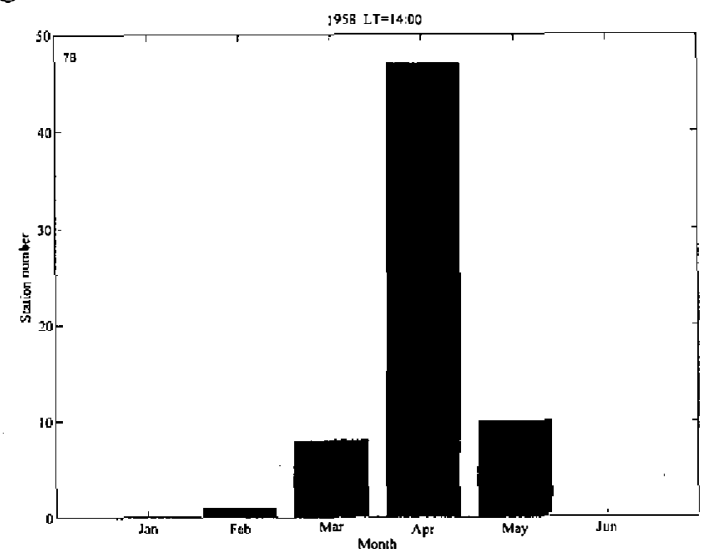

Fig. 7. Phase statistical results at midnight (a) and noon (b) foF2 semi-annual components. The $x$-axis denotes month from January to June, and the $y$-axis indicates how many stations reached the foF 2 peak in respective month.

(Rishbeth 1998; Millward et al. 1996; Fuller-Rowell 1998).

As an example, we focus on the ionosphere at mid-high latitude. During the daytime, there is strong upwelling caused by solar heating occurring in the summer hemisphere and the equatorial region. Those upwellings are usually rich in nitrogen molecules, at the heights of F2 peak; these nitrogen molecules are prone to diminish the electron concentration by increasing loss terms in Equation (2). Furthermore, because of the solar heating, global thermospheric circulations come from the summer hemisphere to the winter one, which may transport the neutral atmosphere rich of molecule nitrogen to the Polar Regions. At the same time, another subsidiary upwelling caused by particle dumping and Joule heating occurs in the vicinity of auroral oval, which may lead to a thermospheric circulation toward the equator. The two circulations (solar-driven in hot hemisphere and magnetospherically driven in high latitudes) usually meet in the region a few degrees equatorward to the auroral oval and a downwelling come into being. Generally, the downwelling may lead to the increasing of $\left[\mathrm{O} / \mathrm{N}_{2}\right]$ in this region.

In the near pole regions, the downwelling occurs at moderately high geographic latitudes (roughly $50-65^{\circ}$ ) in the daytime, but the solar zenith angle in winter noon is not too large at this latitude (roughly $73-88^{\circ}$ ), so the solar radiation is still strong enough to give considerable photoionization. Therefore, in near pole regions, the electron concentration is not primarily sensitive to the solar zenith angle but to the $\left[\mathrm{O} / \mathrm{N}_{2}\right]$. In contrast, in far pole regions, the downwelling occurs at such high geographic latitude regions that the solar zenith angle at winter noon is nearly $90^{\circ}$, and the solar radiation is too weak to give sufficient photoionization, therefore the electron concentration is very sensitive to solar zenith in far pole regions. So, the two most important differences between the two regions are, (1) the daytime NmF2 is usually large in near pole region and small in far pole regions. (2) From winter to the spring equinox, 
a
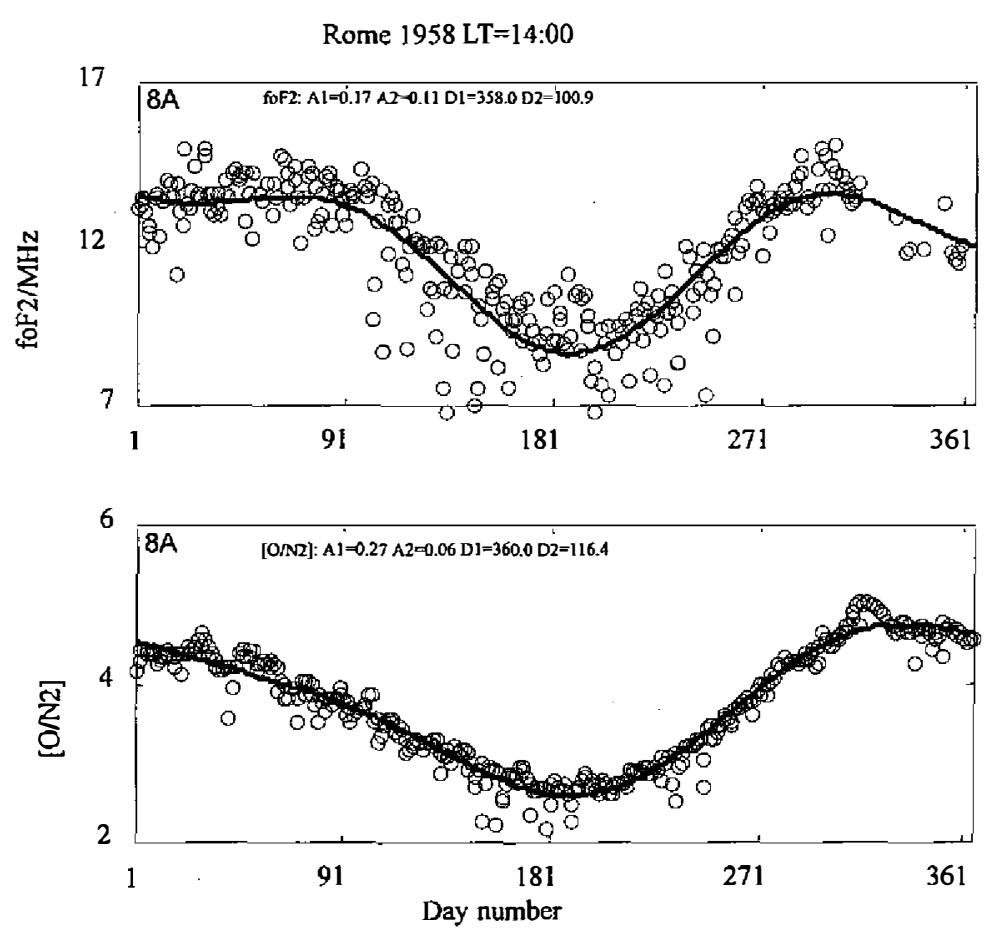

b
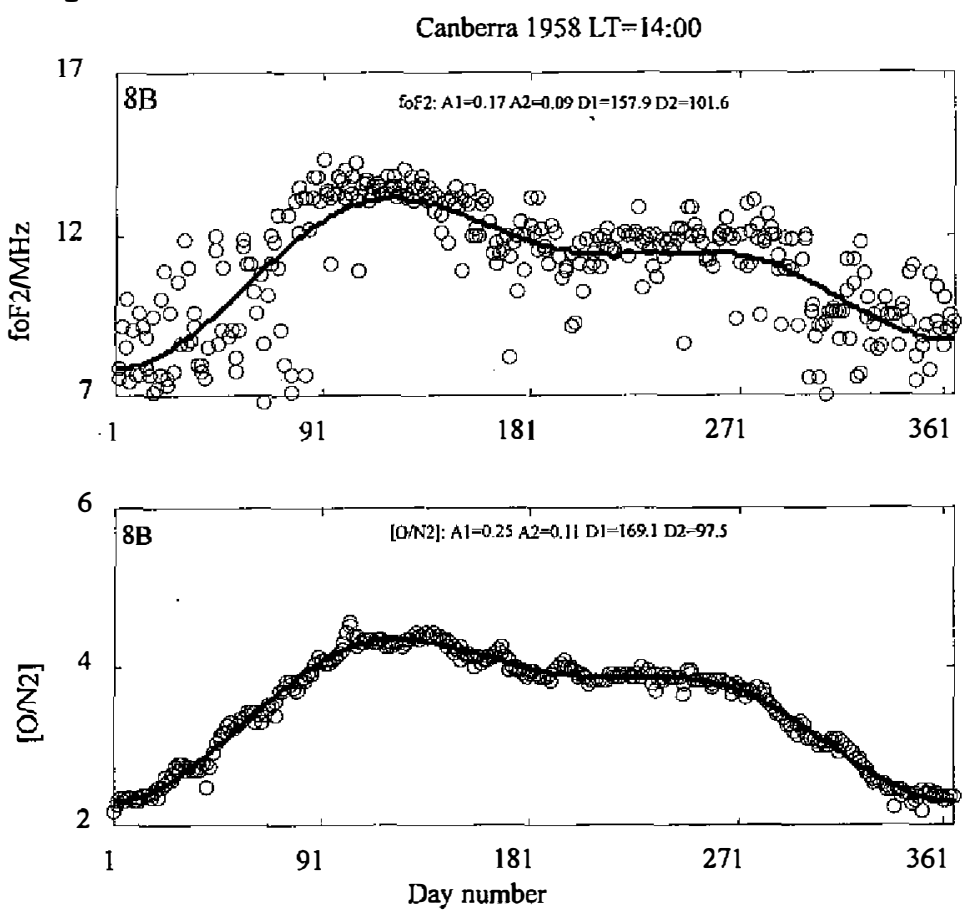

Fig. 8. Variation of noon foF 2 and $\left[\mathrm{O} / \mathrm{N}_{2}\right]$ at Rome (a) and Canberra (b) Stations. In the top panel, the circles and bold solid line respectively represent the measured foF 2 and regression results. In the bottom panel, the circles and solid line respectively represent $\left[\mathrm{O} / \mathrm{N}_{2}\right]$ provided by MSIS 90 and regression results. The amplitudes and phases for annual and semi-annual variations are given in the top of each figure. 
TAO, Vol. 14, No. 1, March 2003

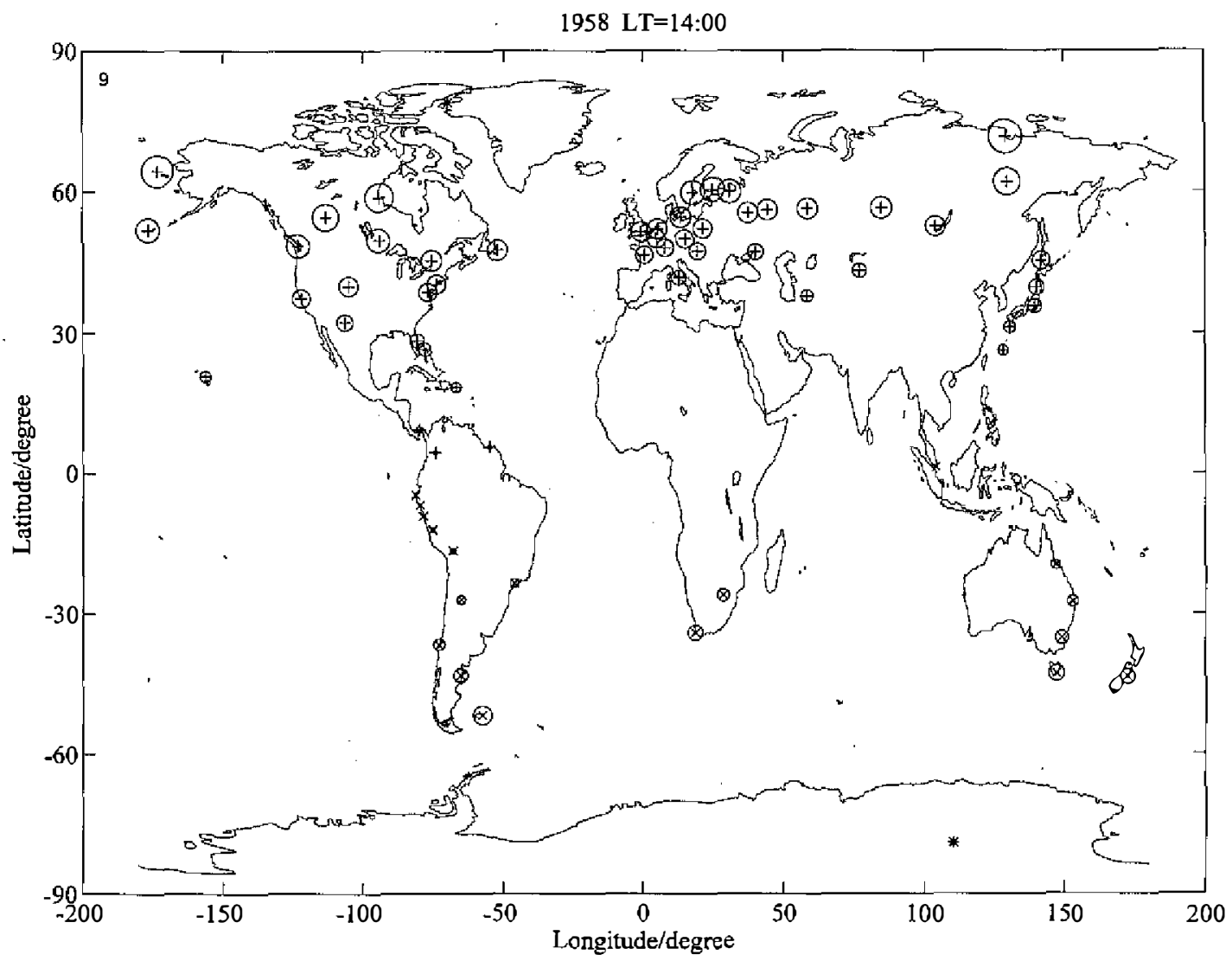

Fig. 9. Global distributions showing the noon $\left[\mathrm{O} / \mathrm{N}_{2}\right]$ annual amplitudes provided by MISIS90 in 1958. The radius denotes the normalized annual amplitude $\left(A_{1} / A_{\bullet}\right)$.

the electron concentration is more sensitive to solar zenith in far pole regions than in near pole regions. This may be seen from Fig. 10, where shows that the change of production rate $\mathrm{q}$ from winter to spring equinox is much larger in far pole regions than that in near pole regions. In addition, since $\left[\mathrm{O} / \mathrm{N}_{2}\right]$ winter anomaly is prevailing at mid-high latitudes (Fig. 9), [O/N $\left.\mathrm{N}_{2}\right]$ decreases remarkably from winter to spring equinox in both the near and far pole regions.

Finally, in the near pole regions, during the whole period from winter to the summer solstice, NmF2 is not sensitive to solar angle, so the NmF2 decrease from winter to summer is due to the decrease of $\left[\mathrm{O} / \mathrm{N}_{2}\right]$. It is much different in the far pole regions. From winter to the spring equinox, NmF2 is very sensitive to solar angle. So, $\mathrm{NmF2}$ increases due to the increasing of production rate. While from spring equinox to summer solstice, the solar zenith angle is small enough to give considerable photoionization and $\mathrm{NmF} 2$ is not sensitive to solar angle any more. So, $\mathrm{NmF} 2$ is primarily controlled shifting from solar zenith angle to $\left[\mathrm{O} / \mathrm{N}_{2}\right]$, and 


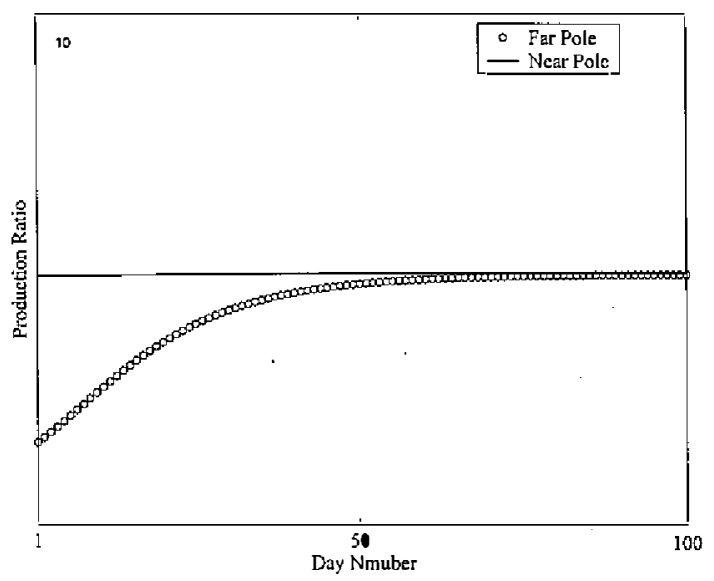

Fig. 10. Production rate variation with day number. The solid line represent the production in near pole region, the circles represent that in far pole region

$\mathrm{NmF} 2$ decreases from spring equinox to summer solstice due to the decreasing of $\left[\mathrm{O} / \mathrm{N}_{2}\right]$.

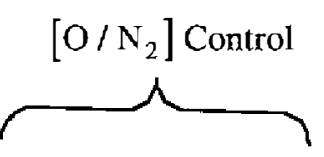

- $\quad \mathrm{NmF2}$ in the Near Pole region: $\{$ Winter $\}>\{$ Equinox $\}>\{$ Summer $\}$

- $\quad \mathrm{NmF2}$ in the Far Pole region: $\{$ Winter $\}<\{$ Equinox $\}>\{$ Summer $\}$

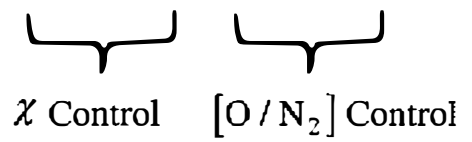

Therefore, in far pole regions, $\mathrm{NmF} 2$ is smaller in winter and summer, larger at the spring equinox; as a consequence, the semi-annual variation is dominant. In near pole regions, $\mathrm{NmF} 2$ is larger in winter, smaller in spring equinox and much smaller in summer; consequently, the winter anomaly is dominant.

\subsection{Physical Discussion for the Semi-annual Variation in the Equatorial Zone}

It may be seen from Fig. $5 b$ that there are pronounced semi-annual variations of daytime foF 2 occurring in the equatorial zone. After examining the neutral compositions calculated by 
TAO, Vol. 14, No. 1, March 2003
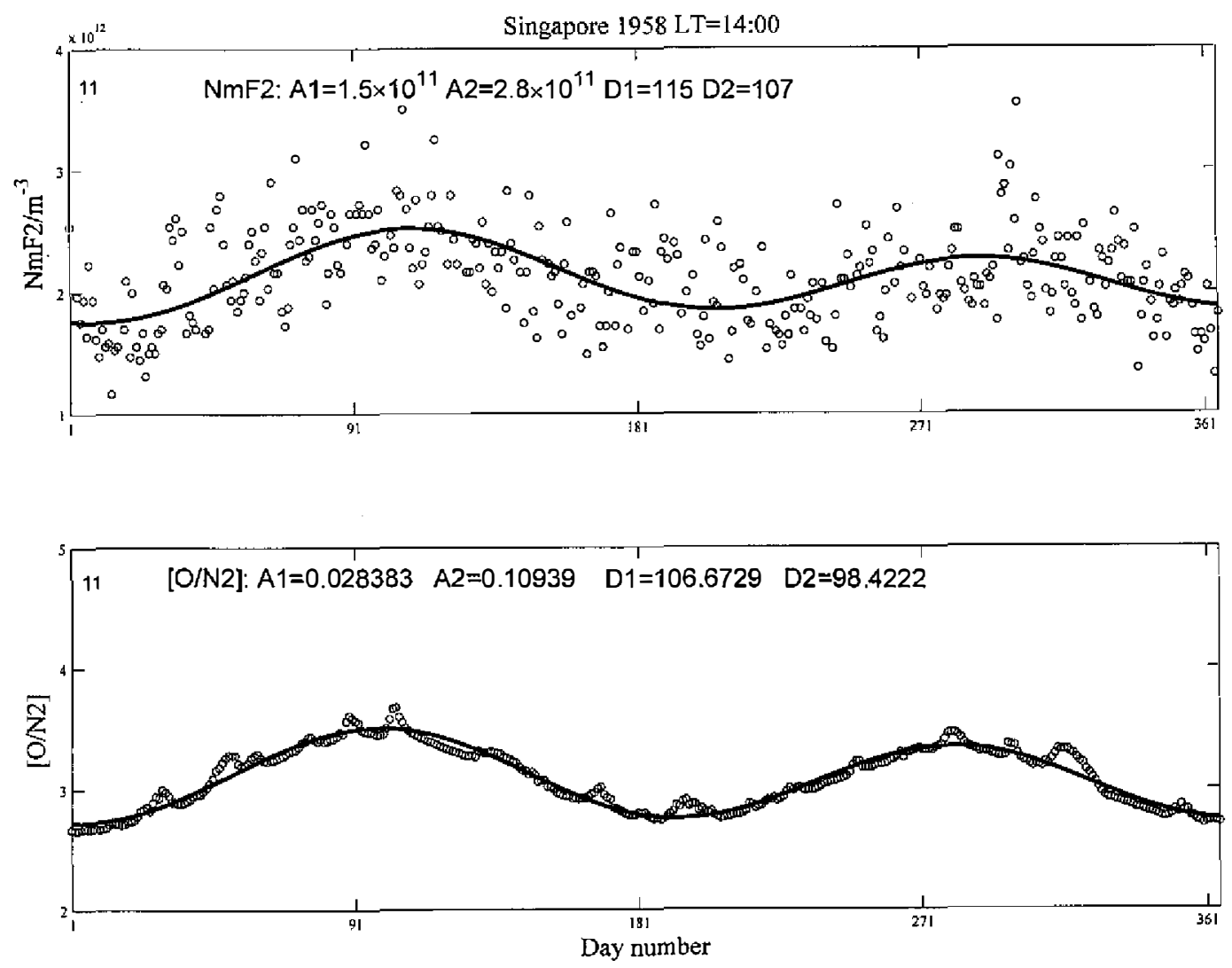

Fig. 11. Noon observed foF2 (top) and calculated $\left[\mathrm{O} / \mathrm{N}_{2}\right]$ (bottom) at Singapore. The circles and solid line denote original data and regression result respectively.

MSIS90, we also find remarkable semi-annual variation of daytime $\left[\mathrm{O} / \mathrm{N}_{2}\right]$ in the equatorial zone. The equatorial station (Singapore) noon $\left[\mathrm{O} / \mathrm{N}_{2}\right]$ calculated by MSIS 90 is shown in the bottom panel of Fig. 11, and foF2 is shown in the upper panel of Fig. 11 too. The circles and solid line in Fig. 11 indicate the original data and regression result respectively. Figure 11 reveals that the observed foF 2 values scatter away from the regression solid line while the calculated $\left[\mathrm{O} / \mathrm{N}_{2}\right]$ converges to the regression solid line, which indicates that the measured foF2 has stronger day-to-day variation than the calculated $\left[\mathrm{O} / \mathrm{N}_{2}\right]$. Moreover, the semi-annual variations of foF2 are very similar to the variation of $\left[\mathrm{O} / \mathrm{N}_{2}\right]$, and both foF 2 , and the $\left[\mathrm{O} / \mathrm{N}_{2}\right]$ variations reach their peaks in the $100^{\text {th }}$ day of a year, close to the spring equinox of the northern hemisphere. In view of this result, we suggest that the foF2 semi-annual variation in the equatorial zone may be partly caused by the semi-annual variation of $\left[\mathrm{O} / \mathrm{N}_{2}\right]$.

As to the foF2 semi-annual variation in the equatorial zone, the aforementioned thermo- 
spheric circulation is another contributor not to be sneezed at. For convenience, we here define a 'prevailing wind' as $\int_{0 L T}^{24 L T} U_{S} \mathrm{dt}$, which indicates the 'net transportation' toward the equator $(>$ 0 ) or the pole region $(<0)$ during a whole day. The larger the prevailing wind is, the stronger the upper atmosphere is mixed by turbulent eddy as a global average (Fuller-Rowell 1998). As a consequence, the molecular compositions, such as nitrogen, are more likely to be moved to F2 regions to diminish foF2. In view of this result, we illustrated the prevailing wind at an equatorial zone station (Singapore) in Fig. 12. It may be seen that the prevailing wind varies as a sine curve during a year, and the prevailing wind is nearly zero at equinox. Therefore, the upper atmosphere is less mixed, so the foF2 increase with the increasing of $\left[\mathrm{O} / \mathrm{N}_{2}\right]$.

Finally, we suggest that both $\left[\mathrm{O} / \mathrm{N}_{2}\right]$ maximization in equinox and prevailing wind minimization in equinox may account for the foF 2 semi-annual variation in the equatorial zone. Other semi-annual phenomena in the upper atmosphere, such as the semi-annual variation of Equatorial Electrical Jet (Liao et al. 2000) and solar wind (Lal 1998; Alicia et al. 2001) and geomagnetic activity (Cliver et al. 2000; Rishbeth and Mendillo 2001), may also contribute to the foF2 semi-annual variation.

\section{CONCLUSIONS}

Observed foF 2 data over 70 stations in a high solar activity year, using the Fourier decomposition method, are studied to investigate the behavior of foF2 annual and semi-annual variations. Firstly, we take an example to illustrate the original data and the Fourier method.

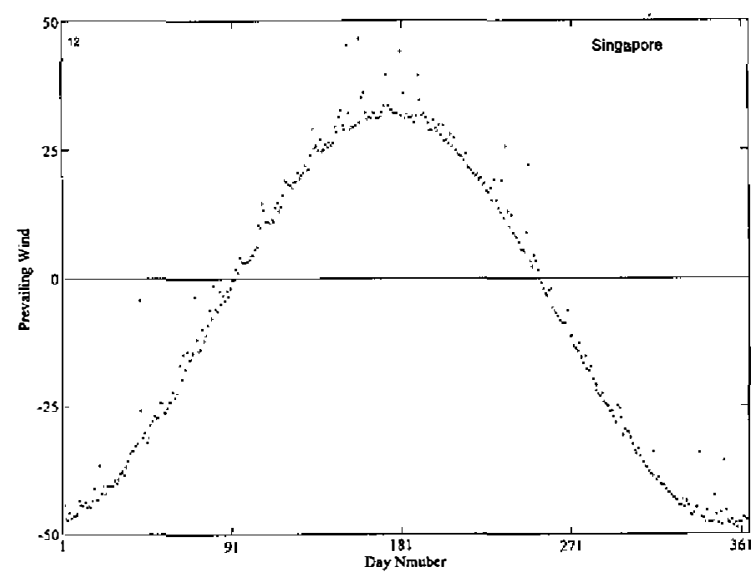

Fig. 12. The 'prevailing wind' variation with day number at Singapore. 
Secondly we study the daytime and nighttime foF2 annual and semi-annual variations in global stations, and show the global distribution features of their amplitudes and phases. Finally, physical mechanisms for the annual and semi-annual variations are discussed and explanations for our results with current theories are given in detail. Main results are briefly recapitulated as follows.

(1) The annual variations appear to be regional characteristics. During nighttime, there is considerable annual variation occurring at mid-high latitudes of both hemispheres, and their phases reveal none of those annual variations are winter anomaly. In daytime, there are pronounced annual variations in mid-high latitudes of both hemispheres; in contrast to the case of nighttime, their phases reveal that all those annual variations are classic winter anomaly, except in South America. Moreover, the annual amplitudes of noon foF2 are larger than those of midnight in South America. On global average, the annual amplitudes of foF2 are much smaller in the southern hemisphere and smallest in the equatorial zone.

(2) The semi-annual variations also appear to be regional characteristics. In nighttime, the semi-annual variations are slightly larger in South America than in other regions. In daytime, there are semi-annual variations in far pole regions and in the equatorial zone. Both in nighttime and daytime, the phase statistical results show that the semi-annual variations usually reach their peak in March and April.

(3) To explain the phenomena mentioned above, we carefully investigate the atomic/ molecular ratio $\left[\mathrm{O} / \mathrm{N}_{2}\right]$ as well as foF 2 . The $\left[\mathrm{O} / \mathrm{N}_{2}\right]$ ratio calculated by empirical model MSIS90 reveal pronounced winter anomaly for $\left[\mathrm{O} / \mathrm{N}_{2}\right]$ all over the world at mid-high latitudes, and we attribute the noon foF 2 winter anomaly prevailing in those regions to the winter anomaly for $\left[\mathrm{O} / \mathrm{N}_{2}\right]$. In the same way, the $\left[\mathrm{O} / \mathrm{N}_{2}\right]$ maximization at equinox as one of the contributors to the foF2 semi-annual variation in the equatorial zone, as is the prevailing wind minimization at equinox.

(4) It is difficult to explain clearly why the daytime semi-annual variations are greater in far pole regions than in near pole regions. We propose the following reason. Since NmF2 is primarily controlled by solar zenith angle, the daytime $\mathrm{NmF} 2$ increases from winter to spring equinox as the daytime production increases. The primary control of $\mathrm{NmF} 2$ shifts to $\left[\mathrm{O} / \mathrm{N}_{2}\right]$ from the spring equinox to summer, and the daytime $\mathrm{NmF} 2$ decreases with the decreasing of $\left[\mathrm{O} / \mathrm{N}_{2}\right]$. Therefore, from winter to the spring equinox and then to summer, NmF2 firstly increases and then decreases, as the final result, and so the $\mathrm{NmF} 2$ semi-annual variation comes into being.

Acknowledgements Special thanks go to Weixing Wan and Libo Liu from Wuhan Ionospheric Observatory, for providing the NOAA CD-ROM used in this work and giving the original ideal and helpful suggestions.

\section{REFERENCES}

Alicia, L. C. G., M. S. Virginia, D. G. Walter, and T. T. Bruce, 2001: Annual variation of geomagnetic activity. J. Atmos. Terr. Phys., 63, 367-374.

Appleton, E. V., and L. J. Ingram, 1935: Magnetic storms and upper atmosphere ionization. 
Nature, 136, 548-549.

Balan, N., Y. Otsuka, G. J. Bailey, and S. Fukao, 1998: Equinoctial asymmertries in the ionosphere and thermosphere observed by the MU radar. J. Geophys. Res., 103, 94819495.

Balan, N., Y. Otsuka, G. J. Bailey, S. Fukao, and M. A. Abdu, 2000: Annual variations of the ionosphere: A review based on the MU radar observations. Adv. Space Res., 25, 153162.

Berkner, L. V., H. W. Wells, and S. L. Seaton, 1936: Characteristics of the upper region of the ionosphere. Terrestrial Magnetism and Atmospheric Electricity, 41,173-184.

Cliver, E. W., Y. Kamide, and A. G. Ling, 2000: Mountains versus valleys: semi-annual variation of geomagnetic activity. J. Geophys. Res., 105, 2413-2424.

Duncan, R. A., 1969: F-region seasonal and magnetic storm behavior. J. Atmos. Terr. Phys., 31, 59-70.

Forbes, J. M., E. P. Scott, and X. Y. Zhang, 2000: Variability of the ionosphere. J. Atmos. Terr. Phys., 62, 685-694.

Fuller-Rowell, T. J., and D. Rees, 1983: Derivation of a conservation equation for mean molecular weight for a two-constituent gas within a three-dimensional, time-dependent model of the thermosphere. Planet. Space Sci., 31, 1209-1222.

Fuller-Rowell, T. J., 1998: The 'Thermospheric spoon': a mechanism for the semi-annual density variation. J. Geophys. Res., 103, 3951-3956.

Johnson, F. S., 1964: Composition changes in the upper atmosphere. In electron density distributions in the ionosphere and exosphere. Ed. E. Thrane, North-Holland, Amsterdam, 81-84 pp.

King, G. A. M., 1964: The dissociation of oxygen and high level circulation in the atmosphere. J. Atmos. Phys., 21, 231-237.

Lal, Chaman, 1998: Solar wind and equinoctial maxima in the geophysical phenomena. $J$. Atmos. Terr. Phys., 60, 1017-1024.

Liao, H. Z., R. P. Ma, J. Y. Xu, and Q. J. Liu, 2000: The semi-annual variation of the Equatorial Electronic Jet. The ninth colloquium of the solar-terrestrial space science in china, $54 \mathrm{pp}$.

Ma, R. P., J. Y. Xu, H. Z. Liao, P. R. Chen, and Q. J. Liu, 2002: foF2 semi-annual and a possible mechanism. Chin. J. Geophys., 45, 766-772.

Millward, G. H., H. Rishbeth, T. J. Fuller-Rowell, A. D. Aylward, S. Quegan, and R. J. Moffet, 1996: Ionospheric F2 layer seasonal and semi-annual variations. J. Geophys. Res., 101, 5149-5156.

Rishbeth, H., and C. S. G. K. Setty, 1961: The F-layer at sunrise. J. Atmos. Terr. Phys., 21, 263-276.

Rishbeth, H., 1998: How the thermospheric circulation affects the ionosphere F2-layer. $J$. Atmos. Terr. Phys., 60, 1385-1402.

Rishbeth, H., I. C. F. Muller-Wodarg, L. Zou, T. J. Fuller-Rowell, G. H. Millward, R. J. Moffett, D. W. Idenden, and A. D. Aylward, 2000a: Annual and semi-annual variations in the ionospheric F2-layer: II. Physical discussion. Ann. Geophysicae, 18, 945-956. 
Rishbeth, H., 2000b: The equatorial F-layer: progress and puzzles. Ann. Geophysicae, 18, 730-739.

Rishbeth, H., K. J. F. Sedgemore-Schulthess, and T. Ulich, 2000c: Semi-annual and annual variations in the height of the ionospheric F2-peak. Ann. Geophysicae, 18, 285-299.

Rishbeth, H., and M. Mendillo, 2001: Patterns of F2-layer variability. J. Atmos. Terr. Phys., 63, 1661-1680.

Torr, M. R., and D. G. Torr, 1973: The seasonal behavior of the F2-layer of the ionosphere. J. Atmos. Terr. Phys., 35, 2237-2251.

Wills, D. M., A. Hewish, H. Rishbeth, and M. J. Rycroft, 1994: Synoptic data for solarterrestrial physics: the U.K. contribution to long-term monitoring. J. Atmos. Terr. Phys., 56, 871-886.

Wright, J. W., 1963: The F region seasonal anomaly. J. Geophys. Res., 68, 4379-4381

Yonezawa, T., and Y. Arima, 1959: On the seasonal and non-seasonal annual variations and the semi-annual variation in the noon and midnight electron densities of the F2 layer in the middle latitudes. J. Radio. Res. Labss., 6, 293-309.

Yu T., W. X. Wan, and L. B. Liu, 2002: Global scale annual and semi-annual variations of daytime NmF2 in the high solar activity years. J. Atmos. Terr. Phys., in revision.

Zou, L., H. Rishbeth, I. C. F. Muller-Wodarg, A. D. Aylward, G. H. Millward, T. J. FullerRowell, D. W. Idenden, and R. J. Moffett, 2000: Annual and semi-annual variations in the ionospheric F2-layer: I. Modeling. Ann. Geophysicae, 18, 927-944. 